\title{
Mobilidade social e empoderamento: a percepção das mulheres beneficiárias do programa Bolsa Família em Minas Gerais
}

Rodrigo Silva Diniz Leroy; Marco Aurélio Marques Ferreira; Nathalia Carvalho Moreira e Edson Arlindo Silva

\section{Introdução}

O Brasil tem apresentado avanços em vários aspectos socioeconômicos, com destaque para a qualidade de vida, o lazer, a educação, o emprego, entre outros. Entretanto, existem áreas que carecem de maior cuidado e atenção, como aquelas presentes no tecido da desigualdade social. Sabe-se que a desigualdade social no Brasil é um problema de abrangência nacional, observando-se realidades díspares, em que se constata alto índice de pessoas em condições de extrema miséria, convivendo com parte da sociedade que apresenta elevada concentração de renda.

Para amenizar esse problema, o governo federal vem, desde 1997, implantando políticas sociais de transferência de renda, entre as quais se destaca o Programa Bolsa Família (PBF), implantado no final de 2003, por meio do qual as familias recebem recurso monetário, com objetivo de promover o alívio imediato da pobreza. O PBF atingiu, em 2010, a marca de 12,4 milhões de famillias atendidas em todo o país, número que faz dele o maior programa de transferência de renda do mundo. 
Segundo Soares et al. (2006), os programas de transferência de renda de natureza não contributiva existem há várias décadas e têm passado por inovações e grande expansão a partir do fim da década de 1990. Esses programas são exemplos de mecanismos diretos de redistribuição, e são utilizados para contribuir com a erradicação da pobreza e a redução substancial dos níveis de desigualdade no Brasil.

Em contrapartida ao benefício, o programa atribui algumas condicionalidades às famílias beneficiárias, tais como manter o cartão de vacinação em dia e a frequência dos filhos na escola, propostas com a finalidade de se ter uma população mais saudável e de diminuir a pobreza do país, já que, teoricamente, essas medidas farão com que, em um futuro próximo, diminua a taxa de analfabetismo, tornando a população mais bem instruída e o mercado de trabalho enriquecido.

Acredita-se que com o PBF, além da previsão de enriquecimento do mercado de trabalho, proporcionado pela educação dos filhos, haja também qualificação em curto prazo, por meio do oferecimento de cursos de capacitação para toda família, o que é considerado fator condicionante da mobilidade social. Sendo assim, é importante verificar em que medida as famílias beneficiárias aproveitam as oportunidades de qualificação profissional.

Em razão disso, esta pesquisa objetivou analisar os impactos que o PBF ocasiona na possibilidade de mobilidade social dos grupos familiares beneficiados, considerando que o seu escopo primordial é ofertar oportunidades àqueles que estão em situação de pobreza e extrema pobreza.

Em termos específicos, pretendeu-se identificar o perfil das famílias beneficiárias, definir os constructos de empoderamento e mobilidade social à luz das teorias utilizadas como arcabouço, bem como a definição desses conceitos na percepção das beneficiárias.

Este estudo está organizado em cinco tópicos. No primeiro tópico, contextualizou-se brevemente o tema a ser abordado, destacando os fatores que influenciaram a realização da pesquisa, bem como se apresentou o problema e sua importância e os objetivos do estudo.

$\mathrm{Na}$ segunda parte, apresentaram-se as principais teorias acerca do tema, e, no item seguinte, abordaram-se os procedimentos metodológicos. Na quarta seção, foram discutidos os resultados obtidos, e, por fim, foram feitas as considerações finais do trabalho, reflexões e sugestões para novos estudos.

\section{Desigualdade social e políticas públicas}

A distribuição de renda de forma diferenciada aos agrupamentos da população é o que caracteriza a desigualdade social, configurada pela detenção da maior parte das riquezas por pequena parcela da população, enquanto pouca porcentagem dos recursos é dividida entre muitos.

De acordo com Giddens (2009), as classes sociais exercem grande influência nas nossas vidas, e a pertença de classe está associada a uma série de desigualdades, desde desigualdades nas expectativas de vida e na saúde física em geral, a desigualdades no acesso à educação e a empregos bem remunerados, cuja divisão permanece no centro das desigualdades econômicas.

O Brasil desponta como um dos primeiros países do mundo em desigualdade social, segundo dados do Instituto de Pesquisa Econômica Aplicada (Ipea), em que, no ano de 2000, a razão entre a renda 
dos $10 \%$ mais ricos e dos $40 \%$ mais pobres, uma medida do grau de desigualdade existente na distribuição de indivíduos segundo a renda domiciliar per capita, ficou em aproximadamente 32,93\%, número consideravelmente alto.

A busca por mudanças nesse patamar é um objetivo a ser alcançado, por exemplo, pela melhor distribuição de renda, estratégia que está surtindo efeito. Prova disso é dada por estudo divulgado em 2008 pelo IPEA, em que foi constatado que três milhões de brasileiros saíram da pobreza nos últimos seis anos e o percentual de famílias pobres caiu de 35\% para 24,1\% da população, nas seis maiores regiões metropolitanas do país, entre 2003 e 2008, o que representa uma redução de cerca de quatro milhões de pessoas.

Os esforços por parte do governo e da população para a diminuição dessa desigualdade não foram, até hoje, suficientes para um grande salto; porém, como se pode ver por meio das estatísticas, a reversão desse quadro vem ocorrendo de forma lenta. Esse crescimento conta com a contribuição de diversas estratégias de combate à fome e à pobreza, entre elas estão os programas de transferência de renda e o PBF, objeto central deste estudo.

Desde a década de 1980 já existiam formas de programas de transferência de renda em alguns países desenvolvidos, entre os quais se destacavam Inglaterra, Alemanha, Holanda, França e Estados Unidos, servindo de exemplo para que, a partir dos anos 1990, essa política fosse introduzida no Brasil (MonteIro, 2008).

O PBF, resultante da fusão dos programas Fome Zero, Bolsa Escola, Bolsa Alimentação e Auxílio Gás, foi implantado pelo governo federal no fim de 2003 e tem como finalidade proporcionar condições mínimas para sobrevivência, por meio de um auxílio financeiro às famílias em situação de pobreza - com renda per capita de até $\mathrm{R} \$ 120$ mensais -, e de extrema pobreza.

Partindo-se de indicações de que as mulheres administrariam os recursos de modo mais favorável à família, o pagamento dos benefícios do programa é preferencialmente feito a elas, algo que, se não tiver neutralidade em relação às relações de gênero, tende a favorecê-las, especialmente

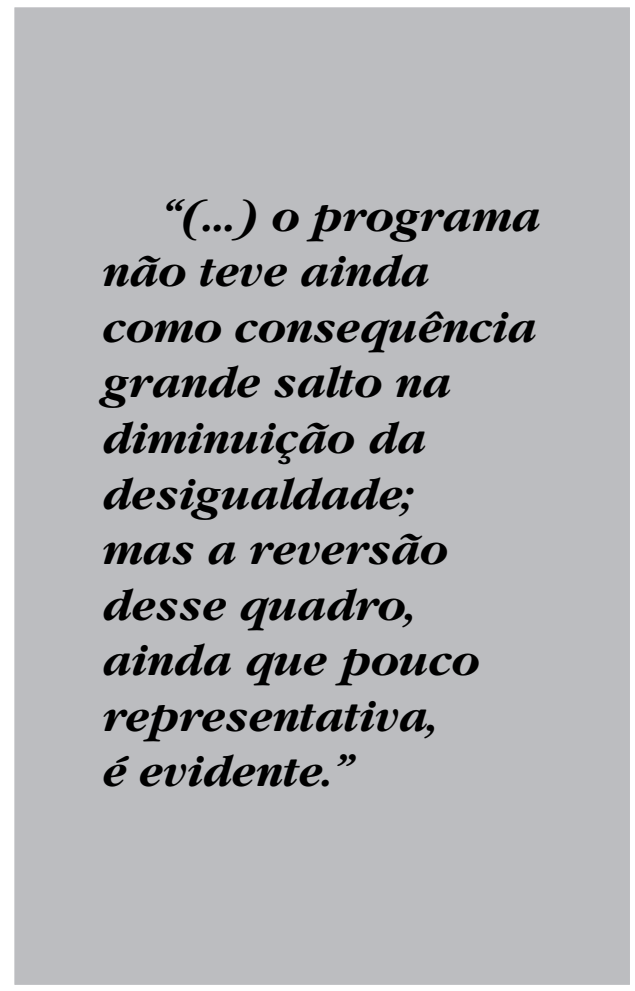

no que diz respeito às relações de poder entre os membros familiares (MEDEIROs et al., 2007).

Nesse âmbito, a incorporação da perspectiva de gênero nas políticas públicas decorreu do processo de democratização do Estado e foi influenciada pelo feminismo internacional, em conferências como a Conferência Mundial sobre 
Direitos Humanos, em 1993, a Conferência sobre População e Desenvolvimento, em 1994, a Conferência Mundial sobre a Mulher, em 1995, além do Fórum Social Mundial, de 2001 a 2003 (FARAH, 2004).

No Brasil, em 2003, a criação da Secretaria Especial de Políticas para Mulheres ampliou as políticas públicas de gênero, expressando o interesse em reverter o padrão de desigualdade, como se observa no trecho do II Plano Nacional de Políticas para as Mulheres:

Deve ser assegurado às mulheres o poder de decisão sobre suas vidas, e de romper com os ciclos e espaços de dependência, exploração e subordinação no plano pessoal, econômico, político e social (BRAsIL, 2008).

Nesse contexto, este trabalho estabelece também diálogo com a literatura feminista em relação aos programas de transferência condicionada de renda (PTCR), que aponta que estes programas reforçam a divisão sexual tradicional do trabalho doméstico, ao impor às mulheres a responsabilidade pelos cuidados com os filhos, atualização do Cadastro Único, entre outros.

Segundo Bronzo (2008), o PBF traz efeitos no reordenamento do espaço doméstico, na autoestima, no empoderamento e acesso feminino ao espaço público (como participação em conselhos comunitários e escolares), possibilitando, às mulheres, maior poder de barganha, maior capacidade de fazer escolhas e maior poder de decisão sobre o uso do dinheiro.

Bronzo (2008) também afirma que existem questionamentos sobre o efeito contrário das transferências de renda, que poderiam perpetuar papéis de submissão de gênero, à medida que a provisão de renda às famílias fizesse com que as mães se retirassem do mercado de trabalho e se dedicassem, exclusivamente, aos cuidados dos filhos.

Soares et al. (2007) atribuem dois objetivos ao Bolsa Família: diminuir a privação de renda de famílias pobres no curto prazo, por meio da transferência monetária, e quebrar o ciclo intergeracional de transmissão da pobreza, por meio do controle do cumprimento das condições de participação relacionadas à educação e à saúde.

Para Bronzo (2008), a busca pela integralidade e articulação das intervenções faz parte da estratégia desse programa de alocação de renda, que é interromper o ciclo de reprodução da pobreza e fortalecer ativos - capital humano, sobretudo - e o acesso a direitos sociais básicos como educação e saúde básica.

A gestão do PBF se faz em três ministérios: do Desenvolvimento Social e Combate à fome, da Educação, que é responsável por fiscalizar a frequência das crianças na escola, e da Saúde, que fica responsável pela atenção a essa área. Esses ministérios agem em harmonia com os estados e municípios, para que o programa seja mais bem fiscalizado e o dinheiro público seja aplicado devidamente.

No âmbito municipal, os Centros de Referência de Assistência Social (Cras) são unidades públicas estatais descentralizadas da política de assistência social, responsável pela organização e oferta de serviços da proteção social básica do Sistema Único de Assistência Social (SUAS) nas áreas de vulnerabilidade e risco social dos municípios e do DF. Dada sua capilaridade nos territórios, se caracteriza como a principal porta de entrada do SUAS, ou seja, é uma unidade que propicia o acesso de grande número de famílias à rede de proteção social de assistência social (MDS, 2010).

As famílias têm também acesso a programas complementares, que são, em sua 
maioria, de educação e qualificação profissional, e que têm por objetivo o desenvolvimento e a superação da situação de vulnerabilidade familiar, visto que, com a capacitação, os membros do grupo familiar terão mais oportunidades de disputar vagas no mercado de trabalho.

Segundo dados do $4^{\circ}$ Relatório de Acompanhamento dos Objetivos de Desenvolvimento do Milênio (IPEA, 2010), são 12,4 milhões de famílias beneficiadas pelo programa, cujos efeitos são percebidos por meio de dados como a queda da pobreza extrema de $12 \%$, em 2003, para 4,8\%, em 2008.

Soares et al. (2006) utilizaram a Pesquisa Nacional por Amostra de Domicílios (Pnad, 2004), que pela primeira vez coletou informação sobre a incidência de alguns programas de transferência de renda. Assim, desenvolveu uma metodologia para separar o componente da renda derivada desses programas, particularmente a renda do Benefício de Prestação Continuada (BPC) e dos outros programas de transferência de renda (como o Programa Bolsa Família). Desse modo, percebeu-se que, conjuntamente, esses programas foram responsáveis por $28 \%$ da redução da queda do índice de Gini $^{1}$ no período 1995-2004 (7\% para o BPC e 21\% para o Programa Bolsa Família). Essa contribuição é grande, se for considerado que esses dois programas somam, de acordo com os dados da Pnad, apenas $0,82 \%$ da renda total das famílias.

Destaca-se a integração estabelecida, no âmbito do sistema de proteção social brasileiro, entre os benefícios de transferência de renda, como o Programa Bolsa Família e o Benefício de Prestação Continuada, além dos serviços ofertados pelos Cras e demais aparatos públicos, com vistas à integralidade da proteção a que se refere Bronzo (2008).

\section{Procedimentos metodológicos}

Este trabalho caracterizou-se como pesquisa predominantemente quantitativa, tratando-se de um estudo de caso múltiplo. Como sujeitos de pesquisa, contou-se com uma amostra de 255 mulheres beneficiárias do PBF, que responderam ao questionário semi-estruturado, contendo 61 questões fechadas, com o objetivo de identificar questões sobre a famillia e sua relação com o PBF.

\section{Análise Exploratória dos Dados (AED) e Alfa de Cronbach}

De acordo com Triola (2008), a Análise Exploratória de Dados (AED) é utilizada para investigação de conjuntos de dados, com o objetivo de compreender suas características importantes, em que são empregadas ferramentas estatísticas (tais como gráficos, medidas de centro e medidas de variação).

Fernandes, Silveira e Ferreira (2010) analisaram o Programa Carta de Crédito no município de Cajuri, localizado na Zona da Mata do Estado de Minas Gerais. Como método principal, utilizou-se a AED, apresentando a frequência absoluta e relativa. Tal técnica mostrou-se adequada e permitiu caracterizar o perfil dos beneficiários, comparar o diagnóstico antes e depois do Programa Carta de Crédito, visando mensurar seus resultados e compreender, pela média, o grau de satisfação das famílias beneficiadas.

De acordo com Pestana \& Gageiro (2005), uma das medidas mais usadas, para verificação da consistência interna de um grupo de variáveis, é o Alfa de Cronbach, que é definido como a correlação esperada entre a escala usada e outras escalas hipotéticas do mesmo universo, com igual número de itens que meçam a mesma característica. 
O teste do Alfa de Cronbach é definido pela fórmula:

$$
\alpha=\frac{n\left(\begin{array}{l}
c o v \\
v a r
\end{array}\right)}{1+(n-1)\left(\begin{array}{l}
c o v \\
v a r
\end{array}\right)}
$$

Em que:

Cov $=$ Média de covariância entre os pares de itens Var $=$ Média de variância entre os pares de itens $\mathrm{n}=$ Número de itens (variáveis)

O Alfa de Cronbach não assume valores negativos, já que as variáveis, que medem a mesma realidade, têm de estar categorizadas no mesmo sentido. Se o valor for negativo, existem correlações negativas, infringindo o modelo de consistência interna e inviabilizando o seu uso. Varia entre 0 e 1, considerando-se a consistência interna, conforme a Figura 1.

\begin{tabular}{ccccc}
$\square$ & $\square$ & & $\square$ \\
\hline 0 & 0,25 & 0,5 & 0,75 & 1 \\
Péssimo & Fraco & Regular & Bom & Excelente \\
\hline
\end{tabular}

Fonte: Elaborado pelos autores.

Figura 1: Valores do teste do Alfa de Cronbach

Para se fazer a análise da consistência interna, é necessário compreender a média, o desvio padrão e a correlação dos itens, tal como o efeito que cada item produz na média, na variância e no Alfa de Cronbach do fator.

De acordo com Schelini \& Wechsler (2006), o constructo é definido como uma análise de modelos teóricos capazes de elucidá-lo, de modo que a elaboração dos itens não seja intuitiva. Para garantir que os constructos apresentem o que eles representam, as variáveis que os constituíram foram cuidadosamente escolhidas.
Fernandes, Silveira e Ferreira (2010) também utilizaram este teste para garantir a validade e a credibilidade do constructo Grau de Satisfação das famílias beneficiadas em relação ao Programa Carta de Crédito, e para isso utilizou-se o Alfa de Cronbach. Nesse contexto, o melhor modelo apresentou o Alfa de 0,718 , considerado bom, com intervalo ao nível de confiança de $95 \%$, o que significa que o verdadeiro Alfa encontra-se entre 0,607 e 0,809 .

Segundo Pestana \& Gageiro (2005), o coeficiente Ró de Spearman mede a intensidade da relação entre variáveis ordinais e usa, em vez do valor nele observado, apenas a ordem das observações. Por essa razão, utilizamos esse coeficiente para analisar os constructos. Por constatar um valor considerado alto entre eles, serão analisados os constructos de Mobilidade Social e de Empoderamento.

\section{Análise de dependência e teste qui-quadrado}

Uma medida de discrepância existente entre frequências observadas e esperadas é proporcionada pelo teste qui-quadrado (REgAZZI, 1997).

Segundo Regazzi (1997), o teste qui-quadrado pode ser usado principalmente como: teste de aderência, para comprovar o ajustamento de uma função de frequência a dados de observação; teste de independência, usado em conexão com as tabelas de contingência, construídas com o propósito de estudar a relação de dependência entre duas variáveis; e teste de homogeneidade, em que uma das variáveis praticamente representa uma classificação dos elementos em populações distintas.

No teste qui-quadrado, a Hipótese $\mathrm{H}_{1}$, que é a hipótese de dependência das 
variáveis testadas, é aceita sempre que o teste for inferior a 0,05 . Nesse teste, para tirar conclusões sobre a relação existente entre as variáveis, os valores esperados de todas as células são comparados com seus respectivos valores observados.

Outros autores têm utilizado o teste qui-quadrado com procedimentos semelhantes, como Moreira (2010), que utilizou o teste para averiguar a relação entre o PFB e os temas: desigualdade de gênero, empoderamento e mobilidade social. Os pesquisadores mostraram que, das variáveis socioeconômicas, apenas as variáveis "microrregião, cidade, escolaridade, outra fonte de renda e saúde" foram estatisticamente significativas $(p<0,10)$, em relação aos temas analisados.

\section{Análise da igualdade de médias entre fenômenos}

Pestana \& Gageiro (2005) explicitam que o teste $t$ para duas amostras independentes é usado sempre que se tem por objetivo comparar as médias de uma variável quantitativa em dois grupos diferentes de sujeitos, e quando se desconhecem suas variâncias populacionais.

Costa e Eid Jr. (2006) utilizaram o teste de médias para analisar a elaboração de políticas públicas que precisam ter em vista as tendências do comportamento de consumo de alimentos, para que possam focar as ações sociais e, principalmente, as políticas de saúde pública. A análise foi feita por meio de um teste de média, para a identificação das variáveis mais relevantes que interferem no processo de escolha e frequência de consumo de carne bovina e hortaliças.

A expressão do teste $t$ para comparar médias, quando as variâncias são diferentes, é dada por:

$$
T=\frac{\left(\overline{X_{1}}-\overline{X_{2}}\right)}{\sqrt{\frac{S_{1}^{2}}{n_{1}}+\frac{S_{2}^{2}}{n_{2}}}}
$$

Em que:

$\mathrm{n}=$ Amostra

$\mathrm{s}^{2}=$ Variância amostral

$\bar{X}=$ Média

Como exemplo, nota-se também o trabalho de Ney Paulo Moreira et al. (2010),

“(...) ressalta-se

o fato de que as

mulberes que

recebem o benefício

têm baixo grau de

escolaridade,

confirmando a

influência desse

quesito na

acentuação do

nível de pobreza e

na afirmação da

política

puiblica(...)”

que utilizaram os testes de médias com intuito de comparar o desempenho dos programas financiados pelo Programa de Fomento à Pós-Graduação (Prof), da Coordenação de Aperfeiçoamento de Pessoal de Nível Superior (Capes), com o desempenho de outros programas. Concluiu-se que os programas de pós-graduação, vinculados às instituições de ensino que recebem recursos do Prof, apresentaram níveis 
superiores de qualidade em relação aos demais programas.

\section{Resultados da pesquisa}

\section{Perfil das famílias beneficiadas}

Foram entrevistadas beneficiárias do PBF de onze cidades, compreendendo pessoas de um mês até aproximadamente sete anos de recebimento, época da implementação do programa. Todas as constatações foram feitas com base nas respostas das entrevistadas.

A Tabela 1 apresenta análise de medidas de tendência central, como média, mediana e moda, e de medidas de dispersão, como desvio-padrão, assimetria e curtose, o que permite verificar a distribuição e concentração dos dados: em que 113 são casadas (44,31\%) e 52 têm união estável (20,39\%). A escolaridade predominante é de ensino fundamental incompleto (138), representando mais da metade $(54,12 \%)$ do total de beneficiárias. Quanto à cor ou raça, a maioria se autodeclarou parda (42,35\%); em segundo lugar, preta (30,98\%); em terceiro, branca $(25,10 \%)$; e, em quarto, com apenas três respostas, amarela $(1,18 \%)$. Nenhuma beneficiária se considerou indígena.

Em relação à ocupação, 134 beneficiárias $(52,55 \%)$ dedicam-se ao lar, 50 se classificaram como desempregadas $(19,61 \%)$, três são aposentadas, e apenas uma é estudante. As outras 67 desempenham alguma atividade regularmente.

As amostras desse estudo mostram que a quantidade de filhos e/ou dependentes

Tabela 1: Perfil das beneficiárias

\begin{tabular}{l|l|l|l|l|l|l}
\hline & Mínimo & Máximo & Média & $\begin{array}{l}\text { Desvio } \\
\text { Padrão }\end{array}$ & Assimetria & Curtose \\
\hline Idade & 22 & 73 & 38,31 & 9,331 & 0,726 & 0,688 \\
\hline $\begin{array}{l}\text { Filhos e/ou } \\
\text { dependentes }\end{array}$ & 0 & 8 & 2,88 & 1,499 & 0,917 & 0,890 \\
\hline $\begin{array}{l}\text { Meses de recebimento } \\
\text { do Bolsa Família }\end{array}$ & 1 & 84 & 45,98 & 28,260 & 0,08 & $-1,395$ \\
\hline
\end{tabular}

Fonte: Resultados da pesquisa

Analisando os dados, pôde-se traçar um tipo ideal de uma família beneficiária. De acordo com Giddens (1990) "um tipo ideal é construído pela abstração e combinação de um indefinido número de elementos que, embora encontrados na realidade, são raramente ou nunca descobertos nesta forma específica" (GIDDENS, 1990, p. 141-2).

Pudemos verificar que as beneficiárias têm idade média de 38,31 anos, a presença da figura do homem se faz na maior parte das famílias beneficiadas pelo programa, das beneficiárias entrevistadas totalizou 735 , obtendo-se uma média de aproximadamente 2,88 filhos por beneficiária, com média de idade de 11,75 anos e desvio padrão de 6,13, em que, entre esses, as mães recebem por 575 , número que representa $78,23 \%$ do total. Existem ainda os outros 160 que não recebem por algum motivo como principal motivo estaria a idade dos dependentes, que tiveram uma média de 11,75 anos, com um mínimo de 0 (zero) e um máximo de 36 anos. Prova disso é que, 
dos que não recebem por algum motivo, 104 - o que representa 65\% - têm 18 anos ou mais, idade em que o benefício por aquele dependente acaba.

Portanto, o tipo ideal da família beneficiária desse estudo é composto por uma mãe casada de 38 anos, que se dedica ao lar, parda, ensino fundamental incompleto, com 3 filhos, sendo um de 18 anos, outro de 11 e outro de 5, e o benefício é recebido somente pelos dois mais novos, há cerca de 3 anos e 10 meses.

\section{Validação e associação dos constructos}

O constructo "mobilidade social" foi baseado nas variáveis a seguir, juntamente com as respectivas transcrições das perguntas feitas às beneficiárias. É necessário deixar claro que o objetivo desse constructo foi analisar a possibilidade de ocorrência da mobilidade social, por meio da percepção dos acontecimentos por parte das beneficiárias e sua posição sobre alguns assuntos, relacionados aos efeitos que o programa possa surtir na família.

O valor do Alfa de Cronbach desse constructo foi de 0,60 , valor que o classifica como fraco, porém aceitável e relevante para o estudo.

O Quadro 1 apresenta as variáveis que compuseram o constructo de mobilidade social, seguidas das questões que foram analisadas.

O constructo "empoderamento", apresentado no Quadro 2, foi feito com algumas variáveis diferentes em relação ao constructo de mobilidade social.

Esse constructo foi considerado relevante, pois teve o Alfa de Cronbach de

\section{Quadro 1: Constructo Mobilidade Social}

\begin{tabular}{|c|c|c|}
\hline Constructo & Variável & Questão \\
\hline \multirow{6}{*}{ 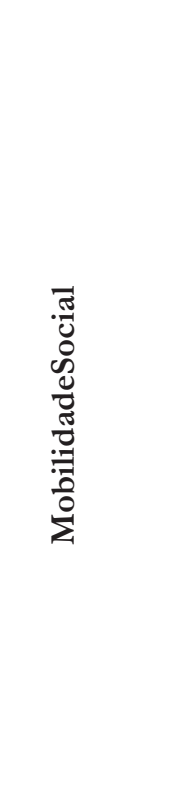 } & $\begin{array}{l}\text { Atendimento às necessidades } \\
\text { básicas }\end{array}$ & $\begin{array}{l}\text { Você concorda que os recursos do } \\
\text { Bolsa Família atendem às necessi- } \\
\text { dades de alimentação, saúde e edu- } \\
\text { cação da família? }\end{array}$ \\
\hline & Acesso ao crédito & $\begin{array}{l}\text { O Bolsa Família aumentou o seu } \\
\text { crédito no mercado? }\end{array}$ \\
\hline & $\begin{array}{l}\text { Acesso a recursos de assistência à } \\
\text { saúde }\end{array}$ & $\begin{array}{l}\text { Com o Bolsa Família, a família teve } \\
\text { mais acesso a médicos e assistência } \\
\text { à saúde? }\end{array}$ \\
\hline & Oportunidades de estudo & $\begin{array}{l}\text { Com o Bolsa Família, a família teve } \\
\text { mais oportunidade de estudar, fazer } \\
\text { cursos de capacitação e quali- } \\
\text { ficação? }\end{array}$ \\
\hline & Estudo dos filhos & $\begin{array}{l}\text { Se o Bolsa Família acabasse, iria } \\
\text { atrapalhar o estudo dos filhos? }\end{array}$ \\
\hline & Necessidade de trabalhar & $\begin{array}{l}\text { Com o Bolsa Família, a mulher pôde } \\
\text { cuidar exclusivamente dos filhos, } \\
\text { sem se preocupar em trabalhar? }\end{array}$ \\
\hline
\end{tabular}

Fonte: Elaborada pelos autores. 
Quadro 2: Constructo Empoderamento

\begin{tabular}{|c|c|c|}
\hline Constructo & Variável & Questão \\
\hline \multirow{6}{*}{ 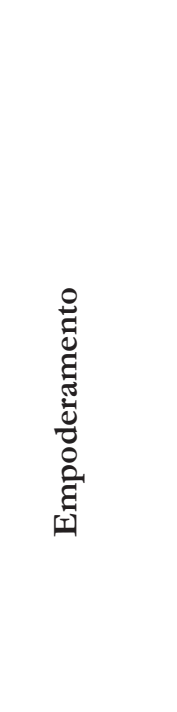 } & Autoridade e respeito & $\begin{array}{l}\text { O Bolsa Família aumentou sua au- } \\
\text { toridade e respeito em casa? }\end{array}$ \\
\hline & Responsabilidades & $\begin{array}{l}\text { Com o Bolsa Família, as suas res- } \\
\text { ponsabilidades pela família aumen- } \\
\text { taram? }\end{array}$ \\
\hline & $\begin{array}{l}\text { Acesso a recursos de assistência à } \\
\text { saúde }\end{array}$ & $\begin{array}{l}\text { Com o Bolsa Família, a família teve } \\
\text { mais acesso a médicos e assistên- } \\
\text { cia à saúde? }\end{array}$ \\
\hline & Oportunidades de estudo & $\begin{array}{l}\text { Com o Bolsa Família, a família teve } \\
\text { mais oportunidade de estudar, } \\
\text { fazer cursos de capacitação e qua- } \\
\text { lificação? }\end{array}$ \\
\hline & Valorização da mulher na sociedade & $\begin{array}{l}\text { O Bolsa Família valoriza a mulher } \\
\text { na sociedade? }\end{array}$ \\
\hline & Valor como cidadã & $\begin{array}{l}\text { O Bolsa Família modificou o seu } \\
\text { valor como cidadã? }\end{array}$ \\
\hline
\end{tabular}

Fonte: Elaborada pelos autores.

0,704. Faz-se necessária a observação de que o desenvolvimento desse constructo partiu do pressuposto de que, com a quantia mensal em dinheiro, o PBF empodera financeiramente as mulheres beneficiárias.

O Quadro 3 apresenta os valores encontrados no coeficiente de correlação Ró de Spearman da pesquisa.

Após avaliação da significância, constatamos que seu valor ficou muito próximo de 0 (zero); por isso, pode-se considerar a correlação como válida. Quanto às análises dos constructos, verificamos que a correlação, medida pelo coeficiente Ró de Spearman, foi de 0,754, valor considerado alto. $\mathrm{O}$ que significa que esses dois constructos têm uma alta e proporcionalmente direta associação, ou seja, quanto maior a percepção de empoderamento por parte das mulheres, maior é a sua propensão à mobilidade social.

\section{Quadro 3: Correlação entre os constructos}

\begin{tabular}{|l|l|l|}
\hline \multicolumn{2}{|c|}{ Coeficiente de correlação Ró de Spearman } \\
\hline & Constructo Mobilidade Social & \\
\hline \multirow{2}{*}{$\begin{array}{l}\text { Constructo } \\
\text { Empoderamento }\end{array}$} & $0,687^{*}$ & Coeficiente de correlação \\
\cline { 2 - 3 } & 0,00 & Significância \\
\cline { 2 - 3 } & 255 & Número de amostras \\
\hline
\end{tabular}

*A correlação é válida ao nível abaixo de 1\% de significância

Fonte: Elaborada pelos autores. 
Estrato do constructo Mobilidade Social

Nesse trabalho classificou-se o constructo de mobilidade social, por meio do estrato, em três níveis: alto, médio e baixo.

Das beneficiárias pesquisadas, o nível de mobilidade social entre elas é predominantemente médio, o que significa que o PBF está surtindo efeito positivo em favor da ascendência social. Porém, como foi dito anteriormente, o programa não teve ainda como consequência grande salto na diminuição da desigualdade; mas a reversão desse quadro, ainda que pouco representativa, é evidente.

A informação acima, sobre o nível de mobilidade social, pode ser mais bem visualizada na Figura 2.

A constatação mais relevante na Figura 2 é quanto à mobilidade por mesorregião pesquisada, em que, no Rio Doce, a discrepância com as outras regiões é enorme. No Rio Doce, o nível baixo de mobilidade $(37,50 \%)$ apresenta um percentual muito maior que as demais regiões constantes na Figura 2. Tamanha diferença pode ser causada, talvez, pelo fato de o município de Vargem Alegre, único representante dessa região na pesquisa, ter o maior índice de incidência da pobreza entre as cidades pesquisadas, com o número de 49,61\%, segundo dados do IBGE (2003).

Essas informações ratificam os resultados encontrados por Moreira (2010), em que foi realizada uma Análise de Cluster, com objetivo de agrupar as mulheres beneficiárias do PBF segundo suas características fundamentais, formando grupos ou conglomerados semelhantes.

Nesse contexto, a região Rio Doce caracterizou-se pelo nível baixo de empoderamento, baixa mobilidade social e baixa desigualdade de gênero, em conjunto com as microrregiões de Caratinga e Muriaé, as quais foram denominadas como grupo de "alta vulnerabilidade" (Moreira, 2010).

Outra informação relevante é quanto à região metropolitana, que, além de ser

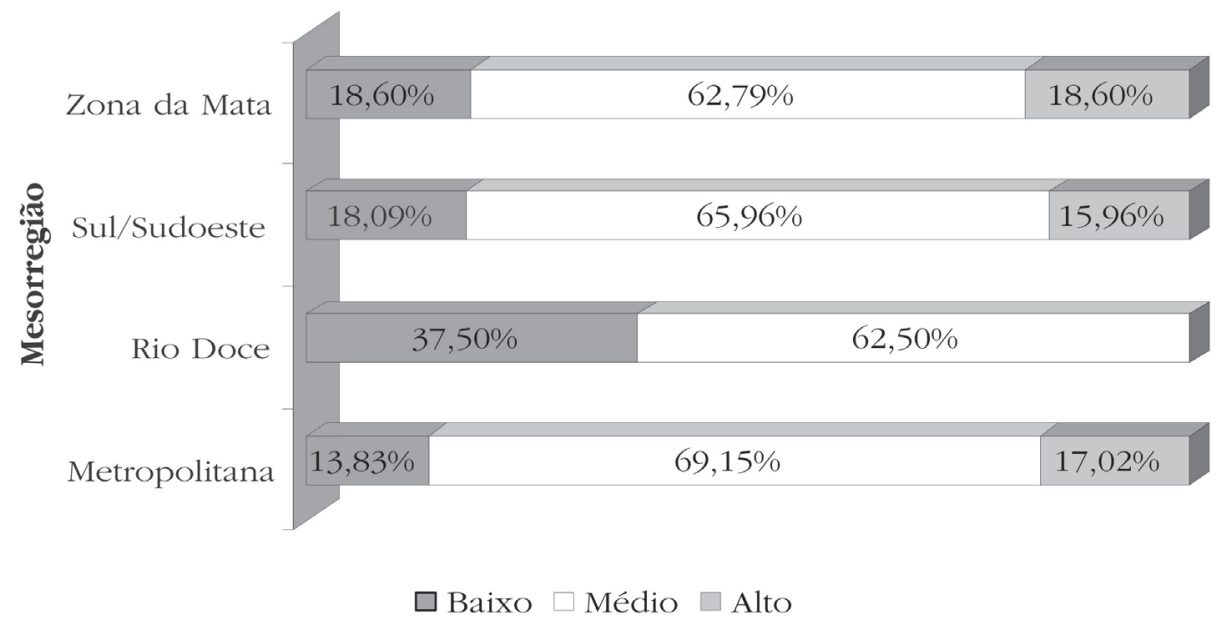

Fonte: Elaborada pelos autores.

Figura 2: Nível de mobilidade social por mesorregião 
pequena a porcentagem das pessoas no nível baixo de mobilidade, tem ainda o maior nível médio entre as quatro regiões; o que quer dizer que, nessa mesorregião, a possibilidade de descendência social é menor e, por consequência, a de ascendência é maior. Esse fato pode ter estreita relação com a concentração metropolitana dos recursos, em que são oferecidas mais oportunidades às pessoas em situação desfavorável dessa região. Esses recursos incluem maiores oportunidades de acesso ao sistema de saúde e educação.

Nesse sentido, retomando Moreira (2010), confirma-se que as famílias da região metropolitana de Belo Horizonte se situam entre os grupos de "baixa vulnerabilidade" e "média vulnerabilidade", sendo classificados como "potencialmente favorecidos" (MoreIrA, 2010).

Conforme a Tabela 2, é possível notar a percepção do oferecimento de oportunidades pelas beneficiárias, visto que, quando questionadas se concordam que com o PBF a família teve mais oportunidades de estudar, fazer cursos de capacitação e qualificação profissional, as respostas, baseadas na escala de Likert, nos permitem essa constatação.

Moreira et al. (2010), em pesquisa realizada no município de Vargem Alegre (região Rio Doce), identificaram que, em todos os arranjos familiares, é predominante o baixo grau de escolaridade tanto das mulheres quanto dos homens, perfazendo mais de $90 \%$ aqueles que pararam de estudar e possuíam o ensino fundamental incompleto.

A principal razão para a interrupção dos estudos, segundo os autores, foi a necessidade de trabalhar para ajudar no sustento da família. Essa baixa escolaridade das entrevistadas justifica, sob alguns aspectos, a submissão da mulher ao marido, a baixa valorização dela na sociedade e as poucas oportunidades de emprego e renda (Moreira et al. 2010).

Dessa forma, tais informações, analisadas em conjunto com os números da presente pesquisa, mostram que na região metropolitana existem mais oportunidades para educação e qualificação profissional; a possível causa disso se deve à concentração industrial nessa região, ao oferecer mais oportunidades de empregos e, consequentemente, maior demanda por mão de obra qualificada.

\section{Considerações finais}

Entre os fatores de destaque, ressaltase o fato de que as mulheres que recebem o benefício têm baixo grau de escolaridade, confirmando a influência desse quesito na

\section{Tabela 2: Percepção das oportunidades de capacitação por mesorregião}

\begin{tabular}{lccccc}
\hline & Sul/Sudoeste & Rio Doce & Zona da Mata & Metropolitana & Total \\
\hline Concordo totalmente & $46,81 \%$ & $37,50 \%$ & $46,51 \%$ & $56,38 \%$ & $49,41 \%$ \\
Concordo em partes & $10,64 \%$ & $0,00 \%$ & $6,98 \%$ & $9,57 \%$ & $8,63 \%$ \\
Concordo pouco & $9,57 \%$ & $12,50 \%$ & $6,98 \%$ & $5,32 \%$ & $7,84 \%$ \\
Indiferente & $14,89 \%$ & $50,00 \%$ & $23,26 \%$ & $17,02 \%$ & $20,39 \%$ \\
Discorda pouco & $0,00 \%$ & $0,00 \%$ & $0,00 \%$ & $0,00 \%$ & $0,00 \%$ \\
Discorda em partes & $2,13 \%$ & $0,00 \%$ & $0,00 \%$ & $0,00 \%$ & $0,78 \%$ \\
Discorda totalmente & $15,96 \%$ & $0,00 \%$ & $16,28 \%$ & $11,70 \%$ & $12,94 \%$ \\
\hline
\end{tabular}

Fonte: Elaborada pelos autores. 
acentuação do nível de pobreza e na afirmação da política pública, visto que a educação dos filhos é prioridade do governo, enquanto condicionalidade para o enquadramento da família nesse programa.

Por intermédio das análises, parece apropriado inferir sobre como é a situação real das beneficiárias, que, apesar de ainda ser desfavorável, grande parte delas tiveram (ou estão propícias a ter) melhorias significativas em suas vidas, a partir da inclusão no PBF. Entre essas melhorias, verificouse que maior quantidade de pessoas, que antes eram classificadas como pobres, elevaram seu patamar social desde a criação do programa, levando-nos a concluir que considerável proporção delas ascendeu socialmente como consequência, principalmente, do recebimento do benefício.

Pôde-se verificar também que as famílias beneficiárias têm mais oportunidades, desenvolvendo competências e capacidade de autodesenvolvimento, o que aumenta sua autonomia. Outra importante constatação foi o fator geográfico, em que a região metropolitana de Belo Horizonte, se comparada às outras, apresenta maior quantidade de oportunidades de trabalho.

Reforçando pesquisas encontradas na literatura, fica então comprovado que o PBF pode surtir efeitos significativos em favor da população desfavorecida no país, contribuindo para a erradicação da pobreza e diminuição das desigualdades encontradas no Estado de Minas Gerais.

Para estudos futuros, sugere-se a replicação desta pesquisa em outras regiões, visando isolar os efeitos de variáveis geossociais, bem como analisar a influência da escolaridade e da atividade de renda complementar na vida das mulheres beneficiárias.

(Artigo recebido em dezembro de 2010. Versão final em dezembro de 2011).

\section{Nota}

${ }^{1} \mathrm{O}$ Índice de Gini é uma medida de concentração ou desigualdade comumente utilizada na análise da distribuição de renda, cujo valor varia de zero (perfeita igualdade) até um (a desigualdade máxima). Fonte: http://www.pnud.org.br/popup/pop.php?id_pop=97

\section{Referências bibliográficas}

Brasil. Presidência da Repúbliva. Secretaria Especial de Políticas para as Mulheres. II Plano Nacional de Politicas para as Mulheres. Brasilia: Secretaria Especial de Políticas para as Mulheres, 2008.

Bronzo, Carla. Vulnerabilidade, empoderamento e proteção Social. Reflexões a partir de experiências latino-americanas. XXXII EnANPAD, 2008. 
Caderno informativo sobre o Índice de Gestão Descentralizada do PBF (IGD). Disponível em: <//bolsafamilia.datasus.gov.br/documentos_bfa/IGD.pdf>. Acesso em: 08 jul. 2010.

Costa, Leonardo Tavares Lameiro da; EID Jr., William. O Efeito Smart Money na Indústria Brasileira de Fundos de Ações. Anais... 30 ENCONTRO DA ANPAD, Salvador, BA, 2006.

FARAh, Martha Ferreira Santos. Gênero e Políticas Públicas. Revista Estudos Feministas, Florianópolis, v.12, n. 1, p. 47-72, 2004.

Fernandes, Cássia do Carmo Pires; Silveira, Suely de Fátima Ramos da; Ferreira, Marco Aurélio Marques. Avaliação de resultados e focalização de políticas habitacionais: investigação do programa Carta de Crédito Associativo no Município de Cajuri - MG. Administração Pública e Gestão Social (APGS), Viçosa, v. 2, n.1, p. 67-85, jan./mar. 2010.

GidDens, Anthony. Capitalismo e moderna teoria social. $3^{\mathrm{a}}$ ed., Lisboa: Editorial Presença, 1990.

. Sociologia. $7^{\text {a }}$ edição. Lisboa: Fundação Caloustre Gulbenkian, 2009.

IBGE. Contagem da População 2007. Disponível em: <http://www.ibge.gov.br/home/ estatistica/populacao/contagem2007/contagem_final/tabela1_1_17.pdf>. Acesso em: 09 jul. 2010.

Incidência da pobreza em Minas Gerais - 2003. Disponível em: <http:// www.ibge.gov.br/cidadesat/comparamun/compara.php?lista $=$ uf\&coduf $=31 \&$ tema= mpobreza2003\&codv $=\mathrm{v} 01 \& \operatorname{codmun}=330455>$. Acesso em: 15 jul. 2010.

Instituto de PesQuisas eCONÔMiCAs aplicadas (IPEA). Relatório Nacional de Acompanhamento. Brasília, 2010. Disponível em: <//www.portalodm.com.br/objetivos-de-desenvolvimento-do-milenio-relatorio-nacional-de-acompanhamento-4--bp--137--np--1.html>. Acesso em: 12 jul. 2010.

. Renda - razão entre a renda dos 10\% mais ricos e $40 \%$ mais pobres. Disponível em: < http://www.ipeadata.gov.br/ipeaweb.dll/ipeadata?SessionID=1541538906\& Tick $=1281618194852 \& V A R \_F U N C A O=S e r \_T e m a s \% 281413839281 \% 29 \& M o d=S>$. Acesso em: 12 ago. 2010.

Medeiros, M; Brito, T; SoAres, F. Programas focalizados de transferência de renda no Brasil: contribuições para o debate. Texto para discussão no 1283, IPEA, 2007.

Ministério DA SAÚde (MS). Relatório consolidado do Bolsa Família MS/SE/DATASUS. Período: $2^{a}$ Vigência de 2009. Disponível em: < http:/ / bolsafamilia.datasus.gov.br/w3c/ consolidados $/$ rel_estado_consol_bfa.asp?gru $=2$ T\&vigencia $=18 \&$ desvig $=0 \% 201 / 1 /$ 2010\%20a\%2030/6/2010\&uf=MG\&regional=00\&cob=1>. Acesso em: 08 jul. 2010. Ministério do Desenvolvimento Social e Combate À Fome (MDS). Centros de referência da Assistência Social. Disponível em: < http://www.mds.gov.br/suas/guia_protecao/crascentros-de-referencia-da-assistencia-social>. Acesso em: 12 jul. 2010.

- Transferência de renda como fator preponderante na diminuição da desigualdade social no Brasil: os efeitos do Programa Bolsa Família. Disponível em: < http://www.ipcundp.org/publications/mds/4P.pdf >. Acesso em: 13 jul. 2010. 
Monteiro, Doraliza Auxiliadora Abranches. Alocação de recursos e eficiência na gestão do Programa Bolsa Família. Viçosa, MG. 78 p. Dissertação (Mestrado em Administração) Programa de Pós-Graduação em Administração, Universidade Federal de Viçosa, 2008. Monteiro, Doraliza Auxiliadora Abranches; Ferreira, Marco Aurélio Marques; TeIXeIrA, Karla Maria Damiano. Determinantes da gestão do Programa Bolsa Família: análise do índice de gestão descentralizada em Minas Gerais. Saude soc., São Paulo, v. 18, n. 2, June 2009. Disponível em: <http://www.scielo.br/scielo.php?script=sci_arttext\&pid= S010412902009000200005\&lng=en\&nrm=iso >. Accesso em: 15 Dec. 2011.

Moreira, Nathalia Carvalho. Programa Bolsa Familia e o empoderamento das mulheres em Minas Gerais. Viçosa, MG. 83 p. Dissertação (Mestrado em Administração) - Programa de Pós-Graduação em Administração, Universidade Federal de Viçosa, 2010.

Moreira, Nathalia Carvalho; Almeida, Anna Laura Teixeira; Ferreira, Marco Aurélio Marques; MatтA, Isabela Braga da. Programa de transferência de renda mínima e atividade complementar de renda: uma análise sobre o empoderamento das mulheres. Revista de C. Humanas, v. 10, no 1, p. 198-212, jan./jun. 2010.

Moreira, Ney Paulo; Silveira, Suely de Fátima Ramos; Ferreira, Marco Aurélio Marques; Cunha, Nina Rosa da Silveira. Eficiência e qualidade dos Programas de Pós-Graduação das instituições federais de ensino superior usuárias do Programa de Fomento à Pós-Graduação (PROF). Avaliação de Políticas Públicas Educacionais (Ensaio), Rio de Janeiro, v. 18, n. 67, p. 365-388, abr./jun. 2010.

Pestana, Maria Helena; Gageiro, João Nunes. Análise de Dados para Ciências Sociais - A Complementaridade do SPSS. $4^{\mathrm{a}}$ ed. Lisboa, 2005.

Pinheiro, Luana et al. Retrato das Desigualdades - Gênero e Raça. IPEA. $3^{a}$ ed. Brasília, 2008. Programa das Nações Unidas para o Desenvolvimento (PNUD). Índice de Gini. Disponível em: <http://www.pnud.org.br/popup/pop.php?id_pop=97>. Acesso em: 14 dez. 2010.

Regazzi, Adair José. Curso de Iniciação à Estatística. Viçosa: Universidade Federal de Viçosa, 2007.

Schelini, Patrícia Waltz; Wechsler, Solange. Estudo da estrutura fatorial da bateria multidimensional de inteligência infantil. Estudos de Psicologia Campinas, v. 23, n. 2, 2006. SoAres, Fábio Veras et al. Programas de Transferência de Renda no Brasil: Impactos sobre a Desigualdade. Ipea, Brasília, Outubro de 2006.

SoAres, Fábio Veras; Ribas, Rafael Perez; Osório, Rafael Guerreiro. Avaliando o Impacto do Programa Bolsa Família: uma Comparação com Programas de Transferência Condicionada de Renda de Outros Países. Centro Internacional de Pobreza, Brasília, Dezembro de 2007.

Triola, Mario F. Introdução à estatística. Tradução Vera Regina Lima de Freitas. $10^{a}$ ed. Rio de Janeiro: LTC, 2008. 


\section{Resumo - Resumen - Abstract}

Mobilidade social e empoderamento: a percepção das mulheres beneficiárias do programa Bolsa Família em Minas Gerais

Rodrigo Silva Diniz Leroy; Marco Aurélio Marques Ferreira; Nathalia Carvalho Moreira e Edson Arlindo Silva

Esse trabalho teve como objetivo analisar os efeitos relacionados à mobilidade social e ao empoderamento das beneficiárias do Programa Bolsa Família em Minas Gerais. Foram utilizados procedimentos metodológicos analíticos, em um estudo de caso múltiplo com abordagem quantitativa. Foi realizada a validação dos constructos de mobilidade social e empoderamento, permitindo-se mensurar a intensidade da relação entre essas diferentes dimensões. Os resultados demonstram a melhoria significativa na vida das beneficiárias, o que pode possibilitar ascendência social. Contudo, observou-se, como fator limitante, o baixo grau de escolaridade das beneficiárias, mostrando-se a necessidade de conexão dos programas sociais com atividades educacionais e de geração de trabalho e renda, para inserção das mulheres no mercado de trabalho. Dessa forma, considera-se que o Programa Bolsa Família pode influenciar significativamente tanto no empoderamento quanto na mobilidade social das beneficiárias. Ademais, a articulação com atividades educacionais e produtivas pode avigorar os resultados de políticas públicas que defendam a justiça social e a diminuição das desigualdades existentes entre gêneros e classes sociais.

Palavras-chave: Políticas públicas, Programa Bolsa Família, mobilidade social, empoderamento.

Movilidad social y empoderamiento: la percepción de de la mujer beneficiarios del programa bolsa familia en Minas Gerais

Rodrigo Silva Diniz Leroy; Marco Aurélio Marques Ferreira; Nathalia Carvalho Moreira y Edson Arlindo Silva

Este estudio tuvo como objetivo analizar los efectos relacionados con la movilidad social y el empoderamiento de los beneficiarios de Bolsa Familia en Minas Gerais. Los procedimientos analíticos metodológicos fueron utilizados en un estudio de casos múltiples con un enfoque cuantitativo para validar los constructos de la potenciación y la movilidad social, lo que le permite medir la intensidad de la relación entre estas diferentes dimensiones. Los resultados demuestran una mejora significativa en las vidas de los beneficiarios como resultado de recibir el beneficio, lo que les permite ascenso social. Sin embargo, se señaló como un factor limitante del bajo nivel de educación de los beneficiarios, destacando la necesidad de conexión con los programas sociales y actividades educativas para generar empleo e ingresos para la integración de las mujeres en el mercado laboral. Por lo tanto, se considera que el Programa Bolsa Família pueda afectar significativamente a la movilidad social y el empoderamiento de los beneficiarios; por otra parte, si los beneficiarios son coordinados con las instituciones educativas y productivas, los impactos esperados pueden ser fortalecidos a través de la implementación de políticas públicas que defiendan la justicia social y la reducción de las desigualdades entre los géneros y clases sociales.

Palabras clave: Políticas públicas, el Programa Bolsa Família, la movilidad social, el empoderamiento. 
Social mobility and empowerment: perceptions of the beneficiaries from the Bolsa Família Program in the state of Minas Gerais (Brazil)

Rodrigo Silva Diniz Leroy; Marco Aurélio Marques Ferreira; Nathalia Carvalho Moreira and Edson Arlindo Silva

This study aims to analyze the effects related to social mobility and empowerment of the beneficiaries from the Bolsa Familia Program in the state of Minas Gerais (Brazil). Analytical procedures were applied in a multiple case study with a quantitative approach. The validation of constructs of empowerment and social mobility enables us to measure the intensity of the relationship between different dimensions. The result shows that the Bolsa Familia program allows the social ascendancy of its beneficiaries. However, it was noted that the beneficiaries' low level of education is a limiting factor. In order to insert women into the labor market it is necessary to associate the Bolsa Família program with other social programs relating to income, education and employment generation. Thus, the Bolsa Família program is able to influence both social mobility and empowerment of its beneficiaries. The Bolsa Família program in association with other social programs (income, education and employment generation) can improve public policies' results related to social justice, gender and social inequality.

Keywords: Public policies, Bolsa Família program, social mobility, empowerment

\section{Rodrigo Silva Diniz Leroy}

Graduando em Ciências Contábeis pela Universidade Federal de Viçosa (UFV), Diretor de Marketing da Cecco - Consultoria Contábil, e pesquisador (Bolsista de Iniciação Científica PROBIC-FAPEMIG), vinculado ao Departamento de Administração e Contabilidade da UFV. Contato: rodrigo.leroy@ufv.br

Marco Aurélio Marques Ferreira

Pós-Doutor em Administração Pública pela Rutgers University - The State University of New Jersey USA. Doutor em Economia Aplicada pela Universidade Federal de Viçosa (UFV). Coordenador do Programa de Pós-Graduação em Administração da UFV. Atual editor da Revista Administração Pública e Gestão Social (APGS). Contato: marcoaurelio@ufv.br

Nathalia Carvalho Moreira

Doutoranda em Administração Pública e Governo pela Fundação Getúlio Vargas (FGV-SP). Mestre em Administração pela Universidade Federal de Viçosa (UFV), Especialista em Gestão Estratégica (UFV) e Graduada em Secretariado Executivo Trilíngue (UFV). Contato: nathaliatp@yahoo.com.br

Edson Arlindo Silva

Doutor em Administração pela Universidade Federal de Lavras (UFLA) e mestre em Extensão Rural pela Universidade Federal de Viçosa (UFV). Professor Adjunto II do Departamento de Administração e Contabilidade do Centro de Ciências Humanas, Letras e Artes da Universidade Federal de Viçosa (UFV). Contato: edson.silva@ufv.br 